

\title{
ROTULAGEM NUTRICIONAL DO QUEIJO DE COALHO DE COMERCIALIZADO NO ESTADO DE PERNAMBUCO
}

\author{
Apresentação: Pôster
}

\begin{abstract}
Keyla Laura de Lira dos Santos ${ }^{1}$; Marcelo José Ferreira Batista ${ }^{2}$; Argélia Maria Araújo3; Marismênia de Siqueira Campos Moura ${ }^{4}$
\end{abstract}

\section{Introdução}

O queijo de coalho está entre os principais produtos derivados do leite típicos da região Nordeste, produzido há mais de 150 anos (Cavalcante et al., 2007). Contudo, a falta de padronização no sistema de produção leva ao mercado produtos bem diversos, em relação à sua composição química, qualidade microbiológica, sensorial e em muitos casos, em desacordo com a legislação vigente.

Os produtos fabricados com leite de búfala, em especial os queijos, apresentam ótima aceitação por parte dos consumidores, tanto pelo seu sabor, quanto por sua qualidade nutricional, como maior teor de cálcio, vitamina A e ácido linoleico conjugado- CLA, ideal para alimentação de crianças e idosos (Teixeira et al., 2005). Além disso, cresce a preocupação da população com escolhas alimentares mais saudáveis, devido ao aumento de doenças de origem alimentar nos últimos anos.

Nesse sentido foram analisadas marcas de queijo comercializadas nos principais mercadinhos e lojas de produtos regionais em cinco municípios pernambucanos quanto ao cumprimento da legislação relativa à informação nutricional. 
${ }^{1}$ Profa, UAST-UFRPE, e-mail: keylasantos@gmail.com

${ }^{2}$ Zootecnista, UFRPE E-mail:marcelofbatista@ hotmail.com

${ }^{3}$ Profa, Codai, E-mail: argeliadias@oi.com.br

${ }^{4}$ Profa, IFPE-Vitória de Santo Antão, E-mail: marismeniascmoura@gmail.com

\section{Fundamentação Teórica}

- A adequação dos rótulos de produtos alimentícios à legislação específica ainda é uma preocupação eminente, pois a fiscalização ineficiente é apontada como principal fator para o descumprimento das normas estabelecidas para a rotulagem de alimentos no Brasil. Dentre as medidas legislativas, destacam-se as Resoluções da Diretoria Colegiada RDC 359 e 360/2003 da ANVISA e Instrução Normativa n²2/2005 do MAPA, importantes na promoção da saúde, além de funcionar como um parâmetro indicativo de qualidade e segurança do alimento.

A rotulagem vem sendo estudada como fonte de informação nutricional para orientar o consumidor sobre a quantidade e a qualidade dos alimentos, promovendo escolhas alimentares mais saudáveis e melhoria da qualidade de vida (Câmara et al., 2008; Lobanco et al., 2009). No entanto, as informações nutricionais contidas nos rótulos devem ser fidedignas para que cumpra o objetivo de auxiliar o consumidor em suas escolhas.

\section{Metodologia}

Foram analisadas quatro marcas de queijo coalho de búfala (A, B, C e D) de fabricação artesanal, uma com selo do Serviço de Inspeção Estadual (SIE) e três, sem certificação, comercializadas nos principais mercadinhos e lojas de produtos regionais, em cinco municípios pernambucanos, Vitória de Santo Antão, Gravatá, Jurema, Tamandaré e Recife, no período de 03 a 11 de dezembro de 2011.

Foram coletadas três amostras por cada marca de queijo, identificadas, acondicionadas em caixa térmica com gelo para que a temperatura não ultrapassasse $10^{\circ} \mathrm{C}$, durante o transporte, e mantidas sob refrigeração para determinação da composição físico-química. As análises de umidade, gordura, gordura no extrato seco e proteína foram realizadas no Laboratório de Nutrição Animal, da Universidade Federal Rural de Pernambuco, e determinadas conforme metodologia descrita pela Instrução da Normativa $\mathrm{n}^{\mathrm{o}}$ 68, de 12 de dezembro de 2006, do Ministério da Agricultura, Pecuária e Abastecimento (BRASIL, 2006). 
O teor de minerais foi determinado pela diferença após a incineração das amostras em mufla a $550^{\circ} \mathrm{C}$ por três horas. As cinzas claras, obtidas após a incineração, foram utilizadas para a determinação do percentual de cálcio (INSTITUTO ADOLFO LUTZ, 2005), que consiste na precipitação do cálcio, na forma de oxalato de cálcio, que é dissolvido em ácido sulfúrico, e o ácido oxálicto que se libera é titulado com permanganato de potássio.

O teor de carboidrato foi obtido pela diferença entre 100 menos o percentual de umidade, gordura, proteína e minerais. O valor calórico (Kcal/100g) foi obtido pela soma dos percentuais de carboidrato e proteína multiplicado por 4 e do teor de gordura multiplicado por 9.

Para avaliação nutricional do rótulo confrontou-se os valores obtidos experimentalmente com os valores energético, de carboidratos, proteínas, gorduras e cálcio declarados nos rótulos de queijo de coalho de búfala, conforme a Resolução RDC nº 360/2003 da ANVISA.

\section{Resultados e Discussões}

Os valores médios encontrados para composição química das marcas de queijo variaram de 46,2 a 55,5 g. $100^{-1 g}, 12,6$ a 27,5 g. $100^{-1 \mathrm{~g}}, 28,2$ a 58,0 g. $100^{-1 \mathrm{~g}}, 8,0$ a $24,1 \mathrm{~g} .100^{-1 \mathrm{~g},}, 1,2$ a $3,0 \mathrm{~g} .100^{-1 \mathrm{~g}}$, 2,7 a 3,4 g. $100^{-1 \mathrm{~g}}, 921,5$ a $1211,1 \mathrm{mg} \cdot 100^{-1 \mathrm{~g}}$ e 357,8 a $325,9 \mathrm{kcal} \cdot 100^{-1 \mathrm{~g}}$ respectivamente, para os teores de umidade, gordura, gordura no extrato seco (GES), proteína, carboidratos, minerais, cálcio e valor energético (Tabela 1).

Tabela 1. Composição físico-química de queijo de coalho de búfala (A, B, C e D) comercializado no estado de Pernambuco. Fonte: Própria

\begin{tabular}{|c|c|c|c|c|}
\hline Itens & Queijo A & Queijo B & Queijo C & Queijo D \\
\hline Umidade $\left(\mathrm{g} \cdot 100^{-1} \mathrm{~g}\right)$ & $50,2 \pm 1,6$ & $55,5 \pm 0,9$ & $50,4 \pm 1,8$ & $46,2 \pm 1,5$ \\
\hline Gordura $\left(\mathrm{g} \cdot 100^{-1} \mathrm{~g}\right)$ & $27,5 \pm 0,6$ & $12,6 \pm 1,7$ & $25,2 \pm 1,6$ & $21,3 \pm 1,6$ \\
\hline $\mathrm{GES}^{1}\left(\mathrm{~g} \cdot 100^{-1} \mathrm{~g}\right)$ & $55,2 \pm 0,7$ & $28,2 \pm 3,4$ & $50,8 \pm 2,9$ & $58,0 \pm 2,1$ \\
\hline Proteína $\left(\mathrm{g} \cdot 100^{-1} \mathrm{~g}\right)$ & $17,4 \pm 0,8$ & $24,1 \pm 0,8$ & $18,3 \pm 1,4$ & $8,0 \pm 0,9$ \\
\hline Carboidratos $\left(\mathrm{g} \cdot 100^{-1} \mathrm{~g}\right)$ & $2,2 \pm 0,6$ & $3,0 \pm 0,5$ & $2,9 \pm 1,9$ & $1,2 \pm 0,7$ \\
\hline Minerais $\left(\mathrm{g} \cdot 100^{-1} \mathrm{~g}\right)$ & $2,7 \pm 0,1$ & $4,9 \pm 0,1$ & $3,1 \pm 0,1$ & $3,4 \pm 0,3$ \\
\hline Cálcio $\left(\mathrm{mg} \cdot 100^{-1} \mathrm{~g}\right)$ & $921,5 \pm 55,7$ & $1211,1 \pm 85,9$ & $1001,9 \pm 85,5$ & $925,4 \pm 50,0$ \\
\hline $\begin{array}{l}\text { Valor energético } \\
\left(\text { kcal. } 100^{-1} \mathrm{~g}\right)\end{array}$ & $325,9 \pm 10,2$ & $221,3 \pm 13,6$ & $311,5 \pm 14,3$ & $357,8 \pm 12,9$ \\
\hline
\end{tabular}

1-GES-gordura no extrato seco. 
Embora não haja uma legislação federal específica para produção do queijo de coalho de búfala, o Regulamento Técnico de Identidade e Qualidade do Queijo Coalho, fabricado com leite de vaca, Instrução Normativa no 30 do Ministério da Agricultura, Pecuária e Abastecimento (MAPA), considera que esse deva apresentar umidade 34,0 a 54,9\% com teor de gordura nos sólidos totais entre 35\% e 60\% (BRASIL, 2001). A Resolução da Secretaria de Produção Rural e Reforma Agrária do Estado de Pernambuco-SPRRA n 002, de 19 de abril de 1999, estabelece para o Queijo de Coalho produzido a partir de leite de bovinos e bubalinos no Estado, com destino ao consumo humano, valores diferentes da legislação federal, com teor de umidade entre 46,0\% e 54,9\% e de gordura no extrato seco, entre 24 a 44,9\% (SPRRA, 1999). Portanto, as amostras da marca B, por apresentar umidade de $55,5 \mathrm{~g} \cdot 100^{-1} \mathrm{~g}$ e teor de GES de $28,2 \mathrm{~g} \cdot 100^{-1} \mathrm{~g}$ encontram-se fora do limite superior da Instrução Normativa n³0/ 2001 para umidade, e do limite inferior para gordura nos sólidos totais. Entretanto, considerando a SPRRA n 002/ 1999, os valores de gordura no estrato seco estão adequados.

Observou-se que 50\% dos queijos analisados possuíam rótulo nutricional (queijo A e B) e 50\% eram comercializados, em desacordo com a legislação (queijo C e D), em saco plástico sem qualquer informação nutricional, data de fabricação, prazo de validade, informações sobre os ingredientes, modo de conservação do produto, entre outros. Esta prática além de obrigatória é importante para informar ao consumidor os tipos de nutrientes presentes nos produtos e suas quantidades. Quanto a conformidade dos dizeres de rotulagem das embalagens de queijo de coalho de búfala, apenas uma marca estava em conformidade com legislação estadual, mas em não conformidade com a legislação federal para denominação de venda, lote e medida caseira. Verificou-se não conformidade para informação nutricional em mais de um nutriente analisado, com aquele apresentado no rótulo (Tabela 2).

Tabela 2. Diferença em porcentagem entre os valores encontrado em laboratório e os declarados nas informações nutricionais de rótulos de queijos de coalho de búfala. Fonte: Própria

\begin{tabular}{lcccccc}
\hline \multicolumn{1}{c}{ Marcas de queijo } & $\mathrm{N}$ & $\begin{array}{c}\text { Valor } \\
\text { energético } \\
(\%)\end{array}$ & $\begin{array}{c}\text { Carboidrato } \\
(\%)\end{array}$ & $\begin{array}{c}\text { Proteína } \\
(\%)\end{array}$ & $\begin{array}{c}\text { Gorduras } \\
\text { totais } \\
(\%)\end{array}$ & $\begin{array}{c}\text { Cálcio } \\
(\%)\end{array}$ \\
\hline Queijo A & 1 & +55 & -41 & -9 & +108 & -12 \\
& 2 & +56 & -14 & -13 & +110 & -12 \\
Queijo B & 3 & +47 & -47 & -17 & +101 & -25 \\
& 1 & $\mathrm{sd}$ & -26 & +24 & -13 & +19 \\
& 2 & +11 & +9 & +16 & +10 & +10 \\
\hline
\end{tabular}

$\mathrm{O}$ sinal (+) refere-se à porcentagem em que o teor declarado no rótulo do produto é maior que o detectado pelas análises e o sinal (-) refere-se à 
porcentagem em que o teor declarado no rótulo do produto é menor que o detectado pelas análises. Variação permitida de $\pm 20 \%$ é estabelecida na Resolução RDC nº 360/2003; sd= sem diferença.

Estavam acima do limite superior exigido 50\% das amostras de queijo para valor energético e de gorduras totais. A quantidade de gorduras totais chegou a variar mais de $145 \%$ em alguns casos. Para o teor de carboidratos, $50 \%$ das amostras apresentavam-se fora da faixa de variação permitida, abaixo do limite exigido. Para os teores de proteínas, 17\% das amostras estavam fora dos limites de tolerância permitidos. Observou-se que uma das marcas estava acima do limite superior exigido.

O cálcio foi quem menos diferiu em relação aos valores declarado no rótulo, $8 \%$ das amostras estavam abaixo do limite inferior permitido. Resultados semelhantes foram obtidos por Silva \& Ferreira (2010), o qual verificaram que $82 \%$ dos queijos minas frescal, queijo minas frescal"light" e ricota apresentavam teor de algum nutriente inferior ao informado no rótulo e à variação permitida de $\pm 20 \%$ pela ANVISA. Estes dados evidenciam o não cumprimento da legislação relativa à informação nutricional. Somente a marca de queijo que possuía certificação (SIE) apresentou valores energéticos, gorduras totais e cálcio dentro da variação de $20 \%$.

\section{Conclusões}

As amostras de queijo coalho de búfala estavam em desacordo com a rotulagem nutricional, o que pode afetar a saúde do consumidor. Há necessidade de adequação das legislações estaduais e federal referentes a rotulagem e identidade do queijo de coalho para que as ações de fiscalização sejam eficientes.

\section{Referências}

BRASIL a. Ministério da Agricultura, Pecuária e Abastecimento. Regulamentos Técnicos de Identidade e Qualidade de Manteiga da Terra ou Manteiga de Garrafa, Queijo de Coalho e Queijo de Manteiga. Instrução Normativa $n^{\circ} 30$, de 26 de junho de 2001. Diário Oficial da República Federativa do Brasil. Brasília, 16 julho de 2001.

BRASIL. Ministério da Agricultura, Pecuária e Abastecimento. Instrução Normativa $\mathrm{n}^{\circ}$ 22, de 24 de novembro de 2005. Regulamento Técnico para Rotulagem de Produto de Origem Animal Embalado. Diário Oficial da União. Brasília, 25 de novembro de 2005.

BRASIL. Ministério da Agricultura, Pecuária e Abastecimento. Instrução Normativa 68 de 12 de dezembro de 2006. Métodos Analíticos Oficiais Físico-Químicos de Produtos Lácteos. Diário 
Oficial da República Federativa do Brasil. Brasília, 14 de dezembro de 2006.

BRASIL a. Ministério da Saúde. Agência Nacional de Vigilância Sanitária. Resolução RDC nº 359 de 26 de Dezembro de 2003. Dispõe sobre regulamento técnico sobre rotulagem nutricional de alimentos embalados. Diário Oficial da República Federativa do Brasil. Brasília, 26 dezembro de 2003.

BRASIL b. Ministério da Saúde. Agência Nacional de Vigilância Sanitária. Resolução RDC n³60 de 23 de Dezembro de 2003. Dispõe sobre regulamento técnico sobre rotulagem nutricional de alimentos embalados. Diário Oficial da República Federativa do Brasil. Brasília, 26 dezembro de 2003.

CÂMARA, M.C.; MARINHO, C.L.C.; GUILAM, M.C. BRAGA, A.M.C.B. A produção acadêmica sobre a rotulagem de alimentos no Brasil. Revista Panamericana Salud Publica, n. 23, v.1, p. 52$58,2008$.

CAVALCANTE, J.F.M.; ANDRADE, N.J.; FURTADO, M.M.; FERREIRA, C.L.L.F.; PINTO, C.L.O.; ELARD, E. Processamento do queijo coalho regional empregando leite pasteurizado e cultura lática endógena. Ciência e Tecnologia de Alimentos, n.27, v.1, p. 205-214, 2007.

INSTITUTO ADOLFO LUTZ. Normas analíticas de Instituto Adolfo Lutz. 4 ed. São Paulo: Instituto Adolfo Lutz, 2005, 1018p.

LOBANCO, C.M.; VEDOVATO, G.M.; CANO, C.B.; BASTOS, D.H.M. Fidedignidade de rótulos de alimentos comercializados no município de São Paulo- SP. Revista de Saúde Pública, n.43, v.3, p.499-505, 2009.

SECRETARIA DE PRODUÇÃO RURAL E REFORMA AGRÁRIA DO ESTADO DE PERNAMBUCO- SPRRA. RESOLUÇÃO N002 DE 19 DE ABRIL DE 1999. Estabelece a identidade e os requisitos mínimos de qualidade que deverá cumprir o Queijo de Coalho produzido no Estado de Pernambuco e destinado ao consumo humano. Disponível em: acesso em: www.adagro.pe.gov.br. Acesso em: 12 de Jan de 2012.

SILVA, L.F.M.; FERREIRA, K.S. Avaliação de rotulagem nutricional, composição química e valor energético de queijo minas frescal, queijo minas frescal“light”" e ricota. Alimento e Nutrição, v. 21, n. 3, p. 437-441, 2010.

TEIXEIRA, L.V.; BASTIANETTO, E.; OLIVEIRA, D.A.A. Leite de búfala na indústria de produtos lácteos. Revista Brasileira de Reprodução Animal, v.29, n.2, p.96-100, 2005. 